\title{
CADÁVERES Y SEXUALIDAD EN VALLE-INCLÁN
}

\author{
FRANCISCO RAmírEZ SANTACRUZ \\ Benemérita Universidad Autónoma de Puebla
}

El marqués de Bradomín posee a Concha -compañera de juegos infantiles y probablemente también antigua amante suya - en la Sonata de otoño (1902) pocos días antes de que ésta muera y cuando ya su enfermedad está muy avanzada. Narra el marqués:

¡Pobre Concha!... Tan demacrada y tan pálida, tenía la noble resistencia de una diosa para el placer. Aquella noche la llama de la pasión nos envolvió mucho tiempo, ya moribunda, ya frenética, en su lengua dorada... Después alcé los ojos para mirarla. Ella cruzó sus manos pálidas y las contempló melancólica. ¡Pobres manos delicadas, exangües, casi frágiles! Yo le dije:

-Tienes manos de Dolorosa.

Se sonrió:

- Tengo manos de muerta.

- Para mí eres más bella cuanto más pálida.

Pasó por sus ojos una claridad feliz:

-Sí, sí. Todavía te gusto mucho y te hago sentir. 
Rodeó mi cuello, y con una mano levantó los senos, rosas de nieve, que consumía la fiebre. Yo entonces la enlacé con fuerza, y en medio del deseo, sentí como una mordedura del terror de verla morir. Al oírla suspirar, creí que agonizaba. ${ }^{1}$

La necrofilia del marqués se hace patente en esta descripción; Concha, ya casi un cadáver, hace vibrar a su amante con placer y satisfacción sexual. La palidez y la enfermedad del cuerpo de Concha excitan la pasión carnal del marqués de Bradomín. Como es sabido, la Sonata de otoño termina bajo el signo de lo macabro; una vez muerta Concha, el marqués la lleva en sus brazos hacia su alcoba, pero la cabellera del cadáver se enreda en una puerta. El marqués, asustado por la proximidad de la luz del día, cae en pánico y tira con fuerza del cuerpo "hasta que se rompieron los queridos y olorosos cabellos...". ${ }^{2}$ En la acción del marqués de Bradomín no sólo quedan unidos en una imagen eros y thanatos, ${ }^{3}$ sino que también se lleva a cabo la transgresión del tabú de la necrofilia. En la Sonata de invierno, por otra parte, se insinuará fuertemente la posibilidad de transgredir otro tabú, el del incesto, ya que la hija de Bradomín es presentada como su posible víctima.

Los cadáveres y su relación con la sexualidad son una constante en toda la obra de Valle-Inclán y no limitada a las Sonatas. La primera obra de teatro del escritor gallego tiene un título significativo: Cenizas (1899). ${ }^{4}$ La palabra alude a lo perecedero y a la muerte; en esa obra, el espectador acude a la representación, en tres episodios, de la muerte de Octavia Goldoni. Poco a poco, Octavia cae enferma, su semblante se torna pálido, su energía decae; hacia el final de la obra se le escapa la vida y se debate entre las convenciones sociales y su amor por Pedro Pondal. También en obras como Luces de bohemia, La rosa de papel o Las galas del difunto aparece un cadáver. El objetivo del presente artículo es examinar este tema en dos obras de las Comedias bárbaras y en Divinas palabras. Por una parte, me interesa mostrar el carácter transgresor del tratamiento de la sexualidad y la muerte en esas obras, así como señalar que esas escenas

\footnotetext{
${ }^{1}$ Ramón del Valle-Inclán, Sonata de otoño, México, Porrúa, 1969, pp. 105-106.

${ }^{2}$ Ramón del Valle-Inclán, op. cit., p. 123.

${ }^{3}$ Bataille, para quien la máxima realización orgiástica es la muerte, propone una analogía total entre ésta y el momento orgásmico, o el miedo a ésta: "Fear of dying makes us catch our breath and in the same way we suffocate at the moment of crisis". Georges Bataille, Erotism, traducción de Mary Dalwood, San Francisco, City Lights Books, 1986, p. 105.

${ }^{4}$ En 1908 Valle-Inclán decidió darle este nuevo título a la obra: El yermo de las almas. A mi parecer, la palabra yermo también alude a lo estéril, a la no-vida, como lo hace la palabra cenizas.
} 
morbosas pueden ser relacionadas con la tradición española barroca del desengaño y, no solamente, con el decadentismo (Wilde, Baudelaire, etc.) o la novela gótica.

Romance de lobos (1907) es cronológicamente la segunda obra de la trilogía de las Comedias bárbaras; sin embargo, en cuanto a la trama es la última, pues Juan Manuel Montenegro es asesinado por sus propios hijos, cumpliéndose de esta manera su propia profecía: “¡Fui pastor de lobos, y ahora mis ganados me comen!". ${ }^{5}$ La obra gira en torno al arrepentimiento de Montenegro después de la muerte de su esposa, doña María. Montenegro es informado del fallecimiento de su esposa y se siente culpable de la muerte de ésta por haberla hecho tan infeliz y por haberla engañado continuamente con incontables amantes. Mientras esperan la llegada de Montenegro a la casa de doña María, Benita La Costurera y doña Moncha se ponen a la tarea de amortajar el cuerpo. Benita, después de recordar cómo le tocó a ella coserle el vestido de novia y ahora le tiene que coser las mortajas, le pregunta a doña Moncha si deben lavar y peinar el cadáver antes de ponerle el hábito:

Doña Moncha. - A mí esa costumbre me parece un sacrilegio.

Benita La Costurera. — ¿Por qué? ¿No va a comparecer en la presencia de Dios Nuestro Señor? Pues natural es que acuda a ella como a una fiesta, bien lavada y aromada. Nunca debimos haber dejado que el cuerpo se enfriase, Doña Monchina. Ya verá cómo ahora cuesta más trabajo aviarle... (Romance, 245).

Mientras la costurera sale en busca de agua, un gato aparece en escena y se acerca a la cama de la muerta. A su regreso, Benita le informa a doña Moncha cómo los cinco hijos se están repartiendo absolutamente todo lo que hay en la casona. De inmediato, las dos mujeres comienzan a lavar el cuerpo:

Benita La Costurera. - Ya empieza a hincharse... ¿Doña Moncha, no tiene un pañuelo que le atemos para sujetarle la barbeta, que mire cómo se le cae desencajada? ¡Jesús, si parece que nos hace una mueca!

Doña Moncha. - ¡Pobre tía!

Benita La Costurera. - Luego que le hayamos vestido el hábito, le pondremos un salero sobre la barriguiña.

\footnotetext{
${ }^{5}$ Ramón del Valle-Inclán, Romance de lobos. Teatro Español 1970-1971, Madrid, Aguilar, 1972, p 289. En adelante, a renglón seguido y entre paréntesis, Romance y página.
} 
Doña Moncha. - ¿Para qué eso?

Benita La Costurera. - Siempre contiene esta hidropesía de la muerte. Mire cómo tiene las piernas, Doña Monchiña.

Doña Moncha. - No la laves más (Romance, 246-247).

A continuación, las dos mujeres se aplican a vestir a la muerta con el hábito; debido a las dificultades que tienen, se ven obligadas a cortar la mortaja por detrás. Como se ha podido apreciar, toda la escena se centra en la descomposición del cadáver de doña María. Primero se discute si es pertinente lavarlo, después se señala que ya está hinchado y que la quijada la tiene desencajada. Las acotaciones también destacan esta descomposición. En un momento se apunta que de "los labios azulencos [de doña María] renace siempre una saliva ensangrentada" (Romance, 246) o que "aquellas manos frías, cruzadas sobre el pecho se desenredan torpes y caen flojas a lo largo del cuerpo" (Romance, 247); la cabeza, por su parte, rueda sobre los hombros.

Cuando Montenegro llega a la estancia, doña María ya ha sido enterrada; el hidalgo le reprocha al capellán, el padre espiritual de doña María, este hecho. Éste se defiende:

El Capellán. - Se corrompía todo, señor.

El Caballero. - ¡Miseria de la carne!

El Capellán. - Los gusanos le corrían. Formaban nido en la cabeza y bajo los brazos (Romance, 266).

El diálogo, sumamente realista, deja poco a la imaginación. La corrupción del cuerpo de doña María estaba tan avanzada que era necesario sepultarla; Montenegro, sin embargo, pide que lo lleven a la capilla donde enterraron a su mujer. El hidalgo decide levantar la losa para ver a la muerta, creyendo que, tal vez, ésta le hable. En la acotación, Valle-Inclán narra la acción:

El Caballero levanta la tapa del féretro, y en la oscuridad de la cueva albean las tocas del sudario y destella la cruz colocada sobre el pecho, entre las manos yertas. El Caballero se inclina, y un aire de húmeda pestilencia, que le hace sentir todo el horror de la muerte, pone frío en su rostro (Romance, 274; cursivas en el original).

Valle-Inclán se esfuerza por mostrar cada detalle del levantamiento de la losa, desde la cruz que provoca un reflejo hasta la pestilencia que expide el cadáver. La escena no sólo es macabra, sino seguramente, para muchos espectadores o lectores, nauseabunda. 
Si en Romance de lobos el tema del cadáver domina, sobre todo, la Segunda Jornada, en Aguila de blasón (1907) este tema le sirve como marco a toda la obra. Ésta se inicia con un reproche que dirige fray Jerónimo a los feligreses: "Si alguna vez recordáis el frágil barro de que somos hechos, lo hacéis como paganos: os asustan el frío de la sepultura, y el manto de gusanos sobre el cuerpo que pudre la tierra, y las tablas negras del ataúd, y la calavera con sus cuencas vacías". ${ }^{6}$ De nueva cuenta, los gusanos y la descomposición hacen su aparición. Hacia el final de la obra, el tema del cadáver alcanza su momento climático. Para Sumner M. Greenfield "La profanación de tumbas es una especialidad de los hijos de don Juan Manuel". ${ }^{7}$ En efecto, Cara de Plata, amante de La Pichona, es solicitado por su hermano don Farruquiño para que le ayude a robar un cadáver del cementerio con la intención de venderlo al seminario por una onza de oro. Cara de Plata accede a la petición. La búsqueda de un esqueleto en condiciones aceptables comienza. Al abrir la primera tumba, los hermanos se encuentran con una tabla llena de gusanos y huesos que se les desmoronan entre las manos. En el segundo intento tienen más suerte y se topan con una momia que todavía conserva parte del cabello. Reza la acotación: "Meten al muerto de cabeza en el saco y al entrar los pies se desprenden los zapatos deleznables y llenos de gusanos. Cruzado sobre el rocín lo sacan del cementerio; pero como unas veces se escurre y otras se ladea en el camino, para sostenerlo acuerda montar Cara de Plata" (Águila, 120; cursivas en el original). Como con el cuerpo de doña María en Romance de lobos cuyas extremidades y cabeza se mueven para todos lados al ser amortajada, así acaece con el cadáver que los hermanos sacrílegamente roban del cementerio. De allí, los dos hermanos se dirigen a la casa de La Pichona en donde se da una de las escenas más logradas de todo el teatro valleinclanesco. Don Farruquiño solicita a la amante de su hermano un caldero donde pueda hervir a la momia para, de esta forma, desprenderle la carne. Mientras se lleva a cabo esta operación, Cara de Plata y La Pichona tienen en esa misma habitación relaciones sexuales, a la vista del hermano y al sonido borboteante del agua hirviendo. Otra vez la acotación es extremadamente explícita: "Los maullidos del gato continúan en la oscuridad, y acompañan el hervir del agua y el voltear del

\footnotetext{
${ }^{6}$ Ramón del Valle-Inclán, Águila de blasón, Madrid, Espasa-Calpe, 1964, pp. 12-13. En adelante, a reglón seguido y entre paréntesis, Águila y página.

${ }^{7}$ Sumner M. Greenfield, Valle-Inclán: anatomía de un teatro problemático, Madrid, Fundamentos, 1972, p. 77.
} 
cuerpo que cuece en el caldero, asomando unas veces la calavera aún recubierta por la piel, y otras una mano de momia negruzca y engarabitada" (Águila, 123; cursivas en el original). En esta escena vuelve a asociarse la muerte con la presencia de un gato, como sucedió cuando doña María en Romance de lobos es amortajada y se acerca un gato a su cama; asimismo, cabe observar que parece como si no sólo don Farruquiño fuera el único voyeur, sino la momia misma estuviese regocijándose e hirviendo en el caldero, observando los retozos sexuales de la Pichona y Cara de Plata. En casa de la Pichona, una vez más, quedan entrelazados eros y thanatos.

No conforme con lo macabro de la escena presentada, Valle-Inclán le impregna mayor humor negro con las siguientes acciones. El intento por arrancarle la piel a la momia fracasa y los dos hermanos se ven obligados a regresar el cadáver al cementerio antes de que amanezca; en efecto, así lo hacen, sólo que ya no se preocupan por enterrarlo otra vez, sino que les basta con lanzarlo por encima del muro del camposanto: "Farruquiño se afirma el tricornio, se tercia el manteo, coge el saco por el cuello y, dándole dos vueltas en el aire, lo arroja por encima de la tapia. Al caer produce un golpe sordo que tiene un eco en la calle" (Águila, 126; cursivas en el original). El novicio no tiene la menor consideración con los restos humanos, al tratarlos como si fueran un saco de patatas. Finalmente, toda esta escena no sólo se relaciona con las "danzas de la muerte" medievales, sino también puede leerse como una parodia de otras escenas donde el cadáver es lavado (véase Romance de lobos), solamente que aquí la acción se desarrolla en un caldero de agua hirviente y con la intención de quitarle la piel a la muerta.

En Divinas palabras (1920), escrita más de una década después de ambas obras anteriores, dos cadáveres fungen como los motores de la trama. La pugna por el carretón entre Mari-Gaila y Marica del Reino se desata a partir de la muerte de la madre del enano, Juana La Reina. A su vez, la muerte del enano, en la Segunda Jornada, es crucial para el desarrollo de los eventos finales. El mundo de Divinas palabras está lleno de crueldad, en especial hacia el enano, cuya muerte, como atinadamente señala Greenfield, "resulta del sadismo 'deportivo' de los feriantes",, ya que le provocan a Laureano una intoxicación alcohólica; desde el primer momento de la muerte del enano, Valle-Inclán enfatiza el aspecto de la descomposición de su cuerpo. Todavía no está frío

\footnotetext{
${ }^{8}$ Sumner M. Greenfield, op.cit., p. 171.
} 
el cadáver del infeliz hidrocéfalo, cuando ya "Las moscas del ganado acudían a picar en ella [la cabeza]" . Llegada la oscuridad Mari-Gaila le ordena a su hija, Simoniña, llevar el carretón con el cadáver del enano a la casa de Marica del Reino. Esa misma noche, el cuerpo de Laureano es atacado y devorado en cara y manos por los cerdos del lugar. Debido a que no tienen suficiente dinero para el entierro del enano, La Tatula le propone a Mari-Gaila esperar tres días para juntar lo suficiente para los gastos; ésta, sin embargo, le responde con respecto al cuerpo de Laureano: "Tres días no los resiste con estas calores" (Divinas, 1174). Más adelante se continúa en una acotación con la descripción del proceso de descomposición del cadáver, iniciado por las moscas a la hora de su muerte: "Encima del vientre, inflamado como el de una preñada, un plato de peltre lleno de calderilla recoge las limosnas, y sobrenada en el montón de cobre negro una peseta luciente" (Divinas, 1177-1178; cursivas en el original). Pronto la peste empieza a colmar el ambiente; una vieja exclama: “¡Cómo hiede!” (Divinas, 1178) y otra: “¡Corrompe!” (Divinas, 1179).

Hasta aquí parece como si en Divinas palabras no existiese esa comunión entre cadáveres y sexualidad que se ha podido observar en Águila de blasón o Romance de lobos; en realidad, esto no es así, pues esta obra de Valle-Inclán se caracteriza por la importante función que cumple la sexualidad. Mientras que el enano es prácticamente asesinado por los feriantes, en la casa de los Gailos se desarrolla una escena paralela donde el adulterio y la posibilidad del incesto salen a relucir. Pedro Gailo, borracho, en una mano un cuchillo carnicero y, en la otra, un pichel, da voces contra su esposa Mari-Gaila, de la que sospecha, correctamente, que lo engaña con otro: “¡He de vengar mi honra! ¡Me cumple procurar por ella! ¡Es la mujer la perdición del hombre!” (Divinas, 1154). Simoniña intenta calmarlo y llevarlo a la cama para que se acueste, pero el sacristán se resiste. Pedro Gailo empieza, ahora, a ver a su propia hija como un objeto sexual que le sirva para satisfacer su deseo y para vengarse del adulterio de su esposa:

Pedro Gailo. - ¡Qué piernas redondas tienes, Simoniña!

Simoniña. - Si toda yo soy repolluda, no había de tener flacas las piernas.

Pedro Gailo. - ¡ Y eres blanca!

Simoniña. - No mire lo que no debe.... Ande para la cama.

\footnotetext{
${ }^{9}$ Ramón del Valle-Inclán, Divinas palabras, Obras escogidas II, Madrid, Aguilar, 1971, p. 1161. En adelante, a renglón seguido y entre paréntesis, Divinas y página.
} 
Pedro Gailo. - ¿Para qué cama, venturosa? Si no has de estar conmigo en la cama no voy a ella.

Simoniña. - Pues deje el cuchillo. ¡Era buena burla acostarnos los dos! Pedro Gailo. - Vamos a jugársela (Divinas, 1156-1157).

Finalmente, Simoniña logra llevar a su padre a la cama, donde éste queda pidiendo a gritos la compañia sexual de su hija. Sin lugar a dudas, esta es una de las escenas más atrevidas de Valle-Inclán. El sacristán se queja del adulterio de su mujer, pero el cuchillo, el pichel y el discurso sobre la honra sólo son una mascarada para encubrir sus verdaderos deseos incestuosos. Inmediatamente después de que los gritos del sacristán se extinguen, inicia la escena de la muerte de Laureano. De esta forma, Valle-Inclán logra asociar la sexualidad de MariGaila y la perversión incestuosa de su esposo con el cadáver del enano.

Ahora que tenemos presente la escena del levantamiento de la losa de la tumba de doña María en Águila de blasón, la escena de la momia metida en el caldero de agua hirviente en casa de La Pichona en Romance de lobos y la muerte de Laureano con su escena paralela entre Simoniña y su padre, es el momento de atar cabos. En Águila de blasón estamos ante un acto necrófilo más o menos al estilo del marqués de Bradomín en la Sonata de otoño; en Romance de lobos hacen su aparición otras dos perversiones: el voyeurismo y el sadomasoquismo, ya que, como después nos enteraremos en Cara de Plata (1922), las relaciones sexuales entre La Pichona y el más joven de los hijos de Montenegro están bajo el signo del sadomasoquismo. Durante uno de sus encuentros amorosos, La Pichona le dice: "Tú puedes rasgarme la sobrecama con las espuelas, y la carne, si eso te divierte. ¡Pégame! ¡Alégrate!”. ${ }^{10} \mathrm{Y}$ el adulterio y el incesto son temas centrales en Divinas palabras.

El incesto, el sadomasoquismo, la necrofilia y el voyeurismo nos llevan a pensar que, en efecto, Valle-Inclán "muestra la faz perversa de eros". ${ }^{11}$ Temas sexuales que estaban en el aire por los años en que Valle-Inclán escribió sus obras, sobre todo, después de los trabajos seminales de Sigmund Freud como La interpretación de los sueños (1899) o los Tres ensayos sobre teoría sexual (1905). Sin embargo, cabe aclarar que el teatro de Valle-Inclán no tiene como finalidad la representación de perversiones sexuales por sí mismas, sino la representación de éstas como transgresoras de las normas. Las escenas comentadas en las

\footnotetext{
${ }^{10}$ Ramón del Valle-Inclán, Cara de Plata, Madrid, Espasa-Calpe, 1946, p. 97.

${ }^{11}$ Lily Litvak, Erotismo fin de siglo, Barcelona, Antonio Bosch, 1979, p. 159.
} 
páginas anteriores seguramente iban dirigidas contra el sistema burgués de valores morales, un sistema represivo que no entendía la sexualidad humana fuera del matrimonio y de la reproducción. Lily Litvak comenta al respecto:

Asimismo, la variedad de perversiones encontradas en la obra de Valle Inclán reflejan un proceso tan sensible como intelectual de deformación de lo natural que sustrae el acto sexual de la esfera de lo cotidiano. Se convierte en un método sistemático de superar conscientemente la mediocridad de lo natural, y esa pretensión, tanto estética como espiritual, revela un intento de creación frente a la naturaleza. ${ }^{12}$

Las escenas morbosas en la obra de Valle-Inclán están casi siempre asociadas con escenas llenas de erotismo. Sin embargo, siguiendo a Bataille se puede decir del arte de Valle-Inclán que en él "Eroticism taken as a whole is an infraction of the laws of taboos" ${ }^{13}$

Finalmente cabe preguntarse cuál es la tradición de la que provienen las escenas macabras de cadáveres en la obra de Valle-Inclán. El aspecto nauseabundo de estas escenas llevó a Joaquín Casalduero a preferir la oposición "amor y terror"14 a "amor y muerte". Para otros críticos, como Leda Schiavo, "la imaginación macabra de Valle-Inclán se nutre, por un lado, con la literatura del romanticismo tardío y del decadentismo/simbolismo (Darío alarga una mano en la sombra y a Poe me nombra) y, por otro lado, con la más pura tradición española en general y gallega en particular" ${ }^{15} \mathrm{Si}$ bien es cierto que no se puede negar cierta coincidencia de temas entre Valle-Inclán y los decadentistas como Baudelaire, Wilde o Poe, ${ }^{16}$ sí es posible destacar una diferencia radical en el trato de los temas macabros. Poe tiende en muchos de sus relatos hacia lo fantasmagórico, lo casi imposible de creer y lo maravilloso. Valle-Inclán, en cambio, no opta por un tratamiento fantástico del tema, sino por el realismo. Esto, a mi parecer, tiene una relación con la tradición española sobre la que Litvak no abunda más en su ensayo.

\footnotetext{
${ }^{12}$ Lily Litvak, op. cit., p. 87.

${ }^{13}$ George Bataille, op. cit., p. 94.

${ }^{14}$ Joaquín Casalduero, Estudios de literatura española, Madrid, Gredos, 1967, p. 266.

${ }^{15}$ Leda Schiavo, «"Este mundo y el otro bailan pareja": La muerte en Valle-Inclán», en Antonio Carreño (ed.), Actas do segundo congreso de estudios galegos, Vigo, Galaxia, 1990, pp. 256-257; cursivas en el original.

${ }^{16}$ Litvak piensa que "Valle-Inclán entra de lleno en la corriente decadentista del fin de siglo europeo, al inspirar en la necrofilia algunos de sus temas". Lily Litvak, Erotismo fin de siglo, Barcelona, Antonio Bosch, 1979, p. 100.
} 
El ambiente que crea Valle-Inclán en estas escenas macabras tiene reminiscencias claras de la tradición tenebrista de algunos pintores del Barroco y no necesariamente del naturalismo como sugiere Agustín del Saz, comentando el pasaje de la momia en el caldero de agua hirviente: "Este naturalismo fantástico y repulsivo, estas nauseabundas visiones no están exentas de ciertos tintes negros y supersticiosos" ${ }^{17}$ En relación con el mismo pasaje, Emilio González López tiene una opinión distinta:

No hay nada de naturalista en este episodio y sus escenas, sino todo lo contrario. No hay en él la exaltación de la miseria o de la energía, sino la presentación de un fuerte contraste entre el mundo tenebroso y misterioso de la Muerte, del más allá, con sus tintes negros, y el sensualismo morboso del más áca. Si se desean rastrear los antecedentes de este arte habrá que buscarlos en el Barroco: en la pintura de Valdés Leal y Jerónimo de Bosch. ${ }^{18}$

En efecto, la escena en la casa de La Pichona está mas cerca del tenebrismo que del naturalismo. En lo personal me inclino más por Valdés Leal, ya que El Bosco muestra una tendencia mayor hacia la imaginación exuberante y fantástica; en cambio, Valdés Leal trabaja dentro de los límites realistas.

Al hablar de escenas macabras o de tenebrismo en el pintor sevillano Juan de Valdés Leal (1622-1690), vienen a la mente, de inmediato, las dos pinturas en las paredes laterales de la Iglesia del Hospital de la Santa Caridad en Sevilla, conocidas como los Jeroglíficos de las Postrimerías, efectuadas hacia 1671-1672. La segunda de estas pinturas, titulada Finis Gloriae mundi, es la que me interesa en particular. El pintor muestra, en primer plano, los cadáveres de un obispo y de un caballero de la Orden de Calatrava en proceso de descomposición y corroídos por insectos. Al fondo se distingue un tercer cadáver aún más putrefacto que los otros. En la parte superior de la pintura aparece una mano llagada con una balanza, en cuyos platillos están representados alegóricamente los vicios y las virtudes. La pintura de Valdés Leal sobresale por su carácter realista; el cadáver del obispo aparece

\footnotetext{
${ }^{17}$ Agustín del Saz, El teatro de Valle Inclán, Barcelona, Industrial Gráfica, 1950, p. 28.

${ }^{18}$ Emilio González López, El arte dramático de Valle-Inclán, Nueva York, Las Américas, 1967, pp. 86-87. Hormigón apunta más o menos en la misma dirección: “El tenebrismo fue patrimonio de Valdés Leal, de Ribera o de Rembrandt”. Juan Antonio Hormigón, «Valle Inclán y Goya: mirar la historia, construir el arte», en Clara Luisa Barbeito (ed.), Valle Inclán: nueva valoración de su obra, Barcelona, PPU, 1988, p. 98.
} 
momificado, los gusanos le salen por la boca y la nariz, las cucarachas invaden la mitra y los zapatos. Beruete y Moret registra la siguiente anécdota; tal es el realismo que Valdés Leal alcanzó en esta pintura que "Parece que Murillo, cuando su autor le mostró estos cuadros, exclamó: ‘Compadre, esto es preciso verlo con las manos en las narices'". ${ }^{19} \mathrm{Si}$ se recuerda la descripción que se hace del cadáver hinchado de doña María en Romance de lobos ("Los gusanos le corrían. Formaban nido en la cabeza y bajo los brazos"), entonces también aquí se puede afirmar que esto hay que leerlo con las narices tapadas; además, cuando Montenegro abre la tumba de su esposa, una ráfaga de pestilencia le pone frío en su rostro. Tanto en la pintura de Valdés Leal como en las palabras de Valle-Inclán casi se puede oír el caminar de los gusanos sobre el cadáver. Para Beruete y Moret, "ningún pintor de ningún país en época ninguna, concibió nada tan pesismista ni tan macabro". ${ }^{20}$

La gran mayoría de los críticos de arte coinciden en que Valdés Leal interpretó en esta pintura excepcionalmente la ideología de Miguel de Mañara, hermano mayor de la Caridad, "quien concibió la iconografía de dichas pinturas como parte de un mensaje iconográfico que advertía la necesidad de estar preparados para enfrentarse al proceso de la muerte y el juicio para que después pudiera obtenerse la salvación del alma". ${ }^{21} \mathrm{Si}$ se acepta esta interpretación, estaríamos entonces ante una pintura con un tema común del Barroco español: memento mori.

Finalmente queda sólo señalar que si bien el sevillano pudo haber creado su arte bajo la tutela de Mañara, un exponente de la Contrarreforma y todo su bagaje conservador y represivo, el escritor gallego, en cambio, utilizó la tradición tenebrista para afirmar la vitalidad de la sexualidad, para rebelarse contra una moral burguesa y represiva, para que, como diría él, en relación a otro grande de la pintura - El Greco - nos percatemos de " $i$ Cuántas veces en el rictus de la muerte se desvela todo el secreto de una vida!". ${ }^{22}$

\footnotetext{
${ }^{19}$ Antonio de Beruete y Moret, Valdés Leal, Madrid, V. Suárez, 1911, p. 91.

${ }^{20}$ Antonio de Beruete y Moret, op. cit., p. 86.

${ }^{21}$ Enrique Valdivieso, Valdés Leal, Madrid, Museo del Prado, 1991, p. 20.

${ }^{22}$ Ramón del Valle-Inclán, La lámpara maravillosa, Madrid, Espasa-Calpe, 1960, p. 122.
} 


\section{Bibliografía}

Bataille, Georges, Erotism, traducción de Mary Dalwood, San Francisco, City Lights Books, 1986.

Beruete y Moret, Antonio de, Valdés Leal, Madrid, V. Suárez, 1911.

Casal duero, Joaquín, Estudios de literatura española, Madrid, Gredos, 1967.

González López, Emilio, El arte dramático de Valle-Inclán, Nueva York, Las Américas, 1967.

Greenfield, Sumner A, Valle-Inclán: anatomía de un teatro problemático, Madrid, Fundamentos, 1972.

Hormigón, Juan Antonio, «Valle Inclán y Goya: mirar la historia, construir el arte», en Clara Luisa Barbeito (ed.), Valle Inclán: nueva valoración de su obra, Barcelona, PPU, 1988, pp. 89-105.

Litvak, Lily, Erotismo fin de siglo, Barcelona, Antonio Bosch, 1979.

Saz, Agustín del, El teatro de Valle Inclán, Barcelona, Industrial Gráfica, 1950.

Schiavo, Leda, "“Este mundo y el otro bailan pareja": La muerte en Valle-Inclán», en Antonio Carreño (ed.), Actas do segundo congreso de estudios galegos, Vigo, Galaxia, 1990, pp. 251-257.

Umpierre, Gustavo, «Muerte y transfiguración de don Juan Manuel Montenegro (Romance de lobos)», Bulletin of Hispanic Studies, 50 (1973), pp. 270-277.

Val divieso, Enrique, Valdés Leal, Madrid, Museo del Prado, 1991.

Valle-Inclán, Ramón del, Cara de Plata, Madrid, Espasa-Calpe, 1946.

--------, La lámpara maravillosa, Madrid, Espasa-Calpe, 1960.

---------, Águila de blasón, Madrid, Espasa-Calpe, 1964.

---------, Sonata de otoño, México, Porrúa, 1969.

---------, Divinas palabras. Obras escogidas II, Madrid, Aguilar, 1971, pp. 1113-1189.

--------, Romance de lobos. Teatro Español 1970-1971, Madrid, Aguilar, 1972, pp. 227-304. 